\section{Notes:}

*The research and experience upon which this paper is based were made possible by funding from the Dean's Office of the Maxwell School of Citizenship and Public Affairs, and the Center for Instructional Development, both at Syracuse University.

1. Cronin (1991) offers an exceptionally useful overview of excellent teaching, along with a set of suggestions for colleges and universities to encourage and reward it.

2. We drew on the work of Freire (1970), Gardner (1982; 1993), and Knowles (1990).

For a description of these theories, see Canfield and Reeher (1996).

3. Depending on the size of the class, nongraded exercises for this purpose included in-class debates, submitted questions, oneminute papers, journals, and role playing exercises.

4. The idea that this all worked itself out in the final exams, or even later in life, did not appease them; justice could not wait. In fairness to the instructors involved, it should also be noted here that the course was already considered by most students to be a success, relative to other offerings in the college. Given the type of course, this is strong praise indeed. But we wanted more.
5. Syllabi requests should be sent directly to the authors at Department of Political Science, Syracuse University, Syracuse, NY 13244.

\section{References}

Barber, Benjamin R. 1984. Strong Democracy: Participatory Politics for a New Age. Berkeley: University of California Press.

Canfield, Kimberley P., and Grant Reeher. 1996. "Encouraging the Better Angels: On Designing the Introductory Course in American Politics." Paper presented at the Annual Meeting of the American Political Science Association, San Francisco.

Cronin, Thomas E. 1991. "On Celebrating College Teaching." PS: Political Science and Politics. 24: 482-91.

Freie, John F. 1992. "The Individual Learning Contract." PS: Political Science and Politics. 25: 230-34.

Freire, Paulo. 1970. Pedagogy of the Oppressed. New York: Continuum.

Gardner, Howard. 1982. Frames of Mind: The Theory of Multiple Intelligences. New York: Basic Books. ed. 1993. Multiple Intelligences: The Theory in Practice. New York: Basic Books.

Knowles, Malcolm. 1990. Andragogy in Action. San Francisco: Jossey-Bass.

\begin{abstract}
About the Authors
Kimberley P. Canfield is a Ph.D. candidate in political science at Syracuse University's Maxwell School of Citizenship and Public Affairs. Her research concerns theories of political participation and employs narrative accounts of uninvolved citizens to enhance these theories.

Grant Reeher is assistant professor of political science at Syracuse University's Maxwell

School of Citizenship and Public Affairs. He is author of Narratives of Justice: Legislators' Beliefs about Distributive Fairness (1996) and Health Care, Reform, and Distributive Justice (forthcoming), and co-editor of Education for Citizenship: Ideas and Innovations in Political Leaming (1997). He currently serves on the Board of Directors of the APSA's Organized Section on Undergraduate Education.
\end{abstract}

\title{
The Challenge of the Large Lecture Class: Making it More Like a Small Seminar
}

\author{
Thomas R. Hensley and Maureen Oakley, Kent State University
}

Large lecture classes are frequently regarded as a necessary evil. ${ }^{1}$ Such classes have to be offered in many colleges and universities to meet high student demand with limited faculty resources, but teaching a large lecture class can be a formidable task. Lecture halls are typically large, barren, and foreboding. It is difficult to get to know students. Students may seem bored in the impersonal environment and may frequently read newspapers or even leave class in the middle of a lecture. Written work by the students seems out of the question. Lecturing is the primary technique for conducting class, perhaps along with showing a few videos. The administrative details of conducting the class can seem overwhelming.

Although the challenges of teaching a large lecture class are substantial, they are not insurmountable.
The solution is to develop innovative methods of classroom instruction that can reduce, if not eliminate, many of the difficulties inherent in the mass class. In this article, we will discuss teaching techniques we have introduced in a large lecture class in American government at Kent State University which help us make a large lecture class more like a small seminar. ${ }^{2}$ We will also suggest that these techniques can be applied successfully in a broad range of courses, regardless of class size.

\section{An Overview of the American Government Class}

The American National Government class at Kent State is probably similar to introductory American government classes taught at many colleges and universities. The course is required for all political science majors and minors, and it is an optional liberal education requirement for all Kent State students. Several sections of the course are offered each semester, with each section being taught as a separate course by various faculty members. The largest section typically enrolls between 100 and 150 students each semester, and it is this class which is the focus of this article. In an average semester, approximately $70 \%$ of the students take the course to fulfill a liberal education requirement, $25 \%$ of the students are majors or minors, and the other five percent take the course as an elective. The students are predominantly freshmen $(50 \%)$ and sophomores (30\%). The abilities of the students vary widely, but the average student has around a $\mathrm{C}+$ grade average.

In many ways, the class is con- 
ducted as a typical large lecture class. Most class sessions are conducted in a lecture format, although videos and guest speakers are used on occasion. A textbook and reader are required. Janda, Berry, and Goldman's, The Challenge of Democracy (1997), is the text currently being used, although numerous other excellent texts could be adopted. The readers vary from semester to semester. They include Miroff, Seidelman, and Swanstrom's Debating Democracy (1997), McKenna and Feingold's Taking Sides: Clashing Views on Controversial Political Issues (1997); DiClerico and Hammock's Points of View: Readings in American Government and Politics (1995); and Levine's Point-Counterpoint: Readings in American Government (1995). Four multiple choice examinations worth 100 points each are given during the semester.

\section{Making the Large Lecture Class More Like a Small Seminar}

The characteristics described above are typical of large lecture classes, but we are making the claim that our class utilizes techniques that give the large lecture class elements of a small seminar. Before discussing these techniques, we need to consider briefly the characteristics of a small seminar class. Although some variation would surely exist among the lists different people would compile, small seminar classes are typically associated with close, personal faculty-student interactions, the verbal exchange of ideas and opinions, and extensive written work by students with substantial feedback from the faculty instructor.

The Paper/Debate Format. The most important technique we use is a se- ries of six papers and accompanying student debates. These papers and debates are spread throughout the semester, and the topics are taken from the assigned reader. For example, in the fall semester of 1996 students used McKenna and Feingold's Taking Sides, and the six topics were: (1) Is American government dominated by big business? (2) Do political campaigns inform voters? (3) Do we need a strong presidency? (4) Does the government regulate too much? (5) Is capital punishment justified? and (6) Is affirmative action reverse discrimination?

Each student must write a twopage paper on each topic. The students are instructed to summarize both articles on the topic in the first page of their paper and to analyze the articles and indicate their position on the issue in the second page. Each paper is worth 20 points, making the six papers are worth a total

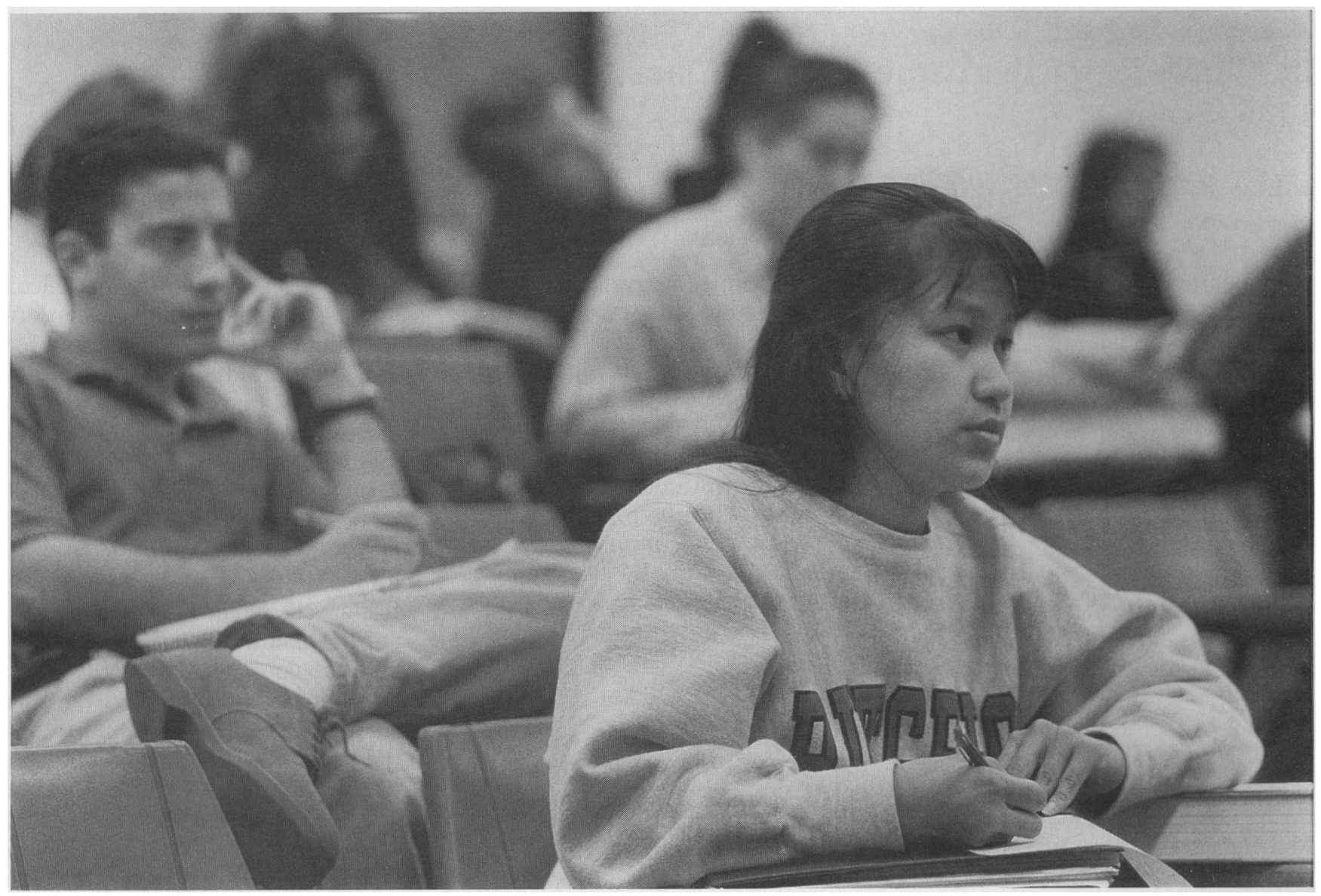

Photo courtesy of Rutgers University 
of 120 points; the papers account for slightly more than 20 percent of the 520 total points students can earn in the course. Each paper is graded on four criteria, which are weighted equally: quality of the summary of the first article, quality of the summary of the second article, quality of the student's analysis, and quality of writing. Students receive ratings of "good," "average," or "poor" for each of the four categories, with 5 points being given for each "good," 3.5 points for each "average" score, and 2 points for a "poor."

Grading the papers is a major undertaking because anywhere from 600 to 1000 papers must be graded each semester. The involvement of teaching assistants, who are typically outstanding senior students majoring in political science, ${ }^{3}$ makes grading the papers manageable. The faculty instructor prepares a detailed grading instruction sheet for each paper. This two-page, single-spaced set of guidelines states the precise criteria for "good," "average," and "poor" performances in regard to each category. The faculty instructor and the teaching assistants sit down together and, using the guidelines, grade a series of papers until a high level of reliability has been achieved. This takes several hours initially, but the process becomes shorter as the teaching assistants gain experience. Once a high level of reliability is achieved, the teaching assistants complete the grading on their own, referring any questions or difficult papers to the faculty instructor.

Papers are normally returned to the students within a week. A cover sheet is given to each student with their score (good, average, poor) for each of the four categories, their total points and grade, and any summary evaluation comments. Written comments addressing both substantive content and writing quality are provided on each paper. In addition, copies of the two-page grading criteria are made available to the students, as are copies of papers which received scores of 20 .

The six debates are closely associated with the papers. During the first week of the semester, students are divided alphabetically into two groups of equal size, with each group assigned a teaching assistant.
Each group, in turn, is divided into six teams of equal size. Depending upon the class size, the teams' memberships range from 8-12 students. Teams from the respective groups are paired together and assigned a particular topic. The two teams debate the assigned topic on the day specified on the syllabus, which is also the day when the paper is due.

Preparation for the debate is not extensive because the students should be well prepared by writing their papers, but teaching assistants do provide some coaching. A week before each debate, the faculty instructor tells both teams the questions that will be raised in the debate. Then a member of each team is asked to come to the front of the class for a coin flip, with the winning side getting to choose which side it wants to take in the debate. At the next class session, the winning side announces which side it has chosen, and both sides meet with their respective teaching assistants to set a time to prepare for the debate. Attendance at the review session is voluntary, but most students attend.

The teaching assistants offer advice on the strengths and weaknesses of the arguments offered by both sides and give hints they think might help their team to win the debate.

An entire 50-minute class session is devoted to each debate. Both teams sit in chairs in the front of the class, with the faculty instructor in a center position acting as the moderator. Following a brief introduction by the faculty instructor and an introduction of all the student debaters, a representative from each group presents a brief summary of his or her team's position. Then the faculty instructor raises the questions which have been provided to the teams. The format is informal; although students must raise their hands and be recognized in order to speak, no set order or other limitations are imposed. The faculty instructor must, of course, be careful to conduct the debate in a fair and impartial manner. During the last ten minutes of the class, the faculty instructor opens the floor to questions from the other members of the class to either team. This is always a lively activity because the students who have been watching the debate are well informed about the topic and welcome the opportunity to challenge some of the ideas advanced in the debate.

The final activity in the debate is a vote in which the students not in the debate choose the winning team. The voting students are carefully instructed before the debate and prior to the vote about the two criteria to be employed when choosing the winners - the quality of the argument presented, regardless of whether one agrees or disagrees with the team's position, and the breadth of participation by the entire team, with at least $50 \%$ participation being required.

Every student on the winning debate team receives 20 bonus points for the course, and each member of the losing team receives 10 . These point values, though small, seem to be enough to encourage students to take the debate seriously and perform well, without being so high as to create problems of overly intense competition and complaints about the process or results.

Other Techniques. We think that the papers/debates help us to provide students all the advantages of small seminars: close student-faculty interactions, the oral exchange of ideas, and extensive written work and feedback. The papers and debates are least effective in producing the first benefit, however, so other techniques are also used to make the large lecture class a more personalized learning experience. The faculty instructor makes a point of talking to each student on a personal basis during the semester. This is accomplished by developing an assigned seating chart and having each student complete a $3 \times 5$ index card listing the student's name, address, phone number, year in school, major, career interests, and a personal note. Before each class, the faculty instructor selects several cards, finds the students according to the seating chart, and chats with the students. By the end of the semester the faculty instructor has spoken personally with each student in the class. The faculty instructor also works to lower the barriers to student-faculty interaction by referring to himself in somewhat informal terms. In this class, the in- 
structor refers to himself as "Dr. Tom" or "H-Bomb," the latter term a joke involving his pathetic attempts to play basketball despite being well beyond the age of 50 . The end result of all these activities is that the instructor can identify most if not all of the students on a firstname basis by the end of the semester.

\section{Student Reaction to the Class}

Are these techniques successful in making the large lecture class more like a small seminar? One way to get an answer to this question is to survey the students in the class. The results we report here are for the class taught in the spring semester of $1996 .{ }^{4}$ Kent State University requires each instructor to administer a "Student Evaluation of Instruction" in every course. This is a 21 -item questionnaire asking six background questions about the student, thirteen specific questions about the course and the instructor, and two general questions, one about the course and one about the instructor. We added a set of 12 supplemental questions, several of which focused on the unique teaching techniques employed in the class. Students could respond to each question on a sixpoint scale: strongly agree, tend to agree, agree, disagree, tend to disagree, and strongly disagree. In determining mean scores, a "strongly agree" response was given a value of " 1 ," and "strongly disagree" was coded as a " 6 ," with the other responses coded accordingly. The questions were all written in such a way that the most positive response from a student would be "strongly agree"; low mean scores are considered positive, like in golf.

Were we successful in turning the large lecture class into a small seminar? We posed this issue to the students in a direct manner: "The teaching techniques used in this course were successful in making a large lecture class more like a small seminar." The mean response on the six-point scale was 1.73 , with $47 \%$ of the students strongly agreeing, another $37 \%$ agreeing with the statement, and another $10 \%$ more tending to agree. Thus, $94 \%$ of the students agreed to some extent with this statement. From the student perspective, then, we did seem to be successful in creating a small seminar environment in a large lecture class.

A closer look at specific items reveals that students thought some techniques were more successful than others. The students gave highly positive responses to most items directly related to the papers and debates:

The seven papers were an effective learning experience-2.09.5

The seven debates were an effective learning experience-1.97.

The papers and debates made this class more fun and interesting1.97.

The paper/debate format should be continued when this course is taught again -1.99 .

Overall, $90 \%$ of the students agreed to some degree that the papers provided an effective learning experience, $91 \%$ agreed that the debates were an effective learning experience, and $94 \%$ agreed that the debates and papers made the class more fun and interesting.

The students also gave favorable responses to questions relating to the effects of the papers and debates on their writing, speaking, and analytical abilities:

Because of the papers and debates in this course, I think I have improved my ability to analyze complex issues for which there are no clear answers-2.37.

I think that my writing skills have improved because of the papers I wrote for this course-2.68.

I think I am a more effective public speaker because of the debates in this course-3.05.

Although these responses are not as positive as those students gave to the previous set of questions, the responses are far from negative: $67 \%$ of the students agreed to some extent that the debates had a positive effect on their public speaking ability, $78 \%$ agreed that the papers helped them improve their writing skills, and $87 \%$ agreed that the papers and debates helped them improve their analytic skills. Substantial emphasis was given throughout the course to the importance of writing and the critical analysis of contending ideas, and extensive feedback was given to the students on each paper. We thought that we could observe significant improvement in the quality of students' writing and analytical skills as the semester progressed, and the student evaluations show that the students also thought their skills had improved.

\section{Discussion}

We have substantial evidence, in the form of student evaluations, that the teaching techniques described in this paper have been successful in making the large lecture class more like a small seminar. In this concluding section, we will discuss some additional benefits of taking this approach to the large lecture class; we will also issue some warnings about potential problems.

An unanticipated but important benefit of teaching the course in this manner has involved the activities of the teaching assistants. The faculty instructor originally decided to involve the teaching assistants because this was the only practical way to ensure that all the papers could be evaluated; the initial thinking was that the teaching assistants would provide an important service to the students in the course. Although the TAs have provided this service, they have also benefitted significantly from the experience. They report enjoying their new status as "junior professors," gaining a very different perspective on college education by being on "the other side of the desk," learning a great deal about American government, and improving their own writing as a direct result of grading other students' papers. A word of warning is in order, however. Undergraduate teaching assistants must be chosen with great care because their activities are critical to the success of the class. Fortunately, every teaching assistant involved in this class has performed well.

A final positive point we want to mention is that these techniques are not limited to large lecture classes; they can be utilized effectively in small and medium-size classes. In regard to using papers and debates, 
most political science courses involve numerous contentious issues that can spark students to analysis and debate. Numerous books have been written which present contrasting positions on controversial political issues. ${ }^{6} \mathrm{~A}$ faculty member is not limited by the availability of relevant books, however. Topics can be selected by the instructor, and then the instructor can assign appropriate articles for the students to read or can assign students to research the topics. The broad relevance of the paper/debate format is perhaps best illstrated by several education majors who took the large lecture American class and reported that they were adapting the debate/paper technique for use in their own secondary and even elementary classes.

Although these teaching techniques have many positive aspects, some real, as well as potential, negative features exist. One concern involves class size. The course has been taught in this format with as many as 150 students, ${ }^{7}$ but this seems to be the upper limit in terms of effective debate teams and grading all the papers. An additional problem is the time commitment required of the faculty instructor. Incorporating these techniques into the class is time-consuming, and this means other activities - such as research -will suffer, or very long hours will be spent each week trying to engage effectively in teaching, research, and service activities. Yet another real cost of using these techniques is the "loss" of six classes which could otherwise be used for lectures, videos, guest speakers, etc. Continuous analysis must be done of the effectiveness of the debates to determine if they are a wise use of class time.

The greatest concern that the faculty instructor had in introducing these techniques was that students would withdraw from the course en masse when they were told on the first day of class that they would have four exams and six papers. This has not happened, however. The withdrawal rate for the course has been a consistent $10 \%$, which is virtually identical to the mean with- drawal rate across the university. It does seem necessary, however, to make a strong, positive appeal to students on the first day, assuring them that the workload is manageable, that the papers and debates are actually fun, and that the benefits are significant in terms of developing students' writing, speaking, and analytical abilities. Students are generally willing to accept challenges and to work hard if they believe in what they are doing. As Thomas Cronin $(1991,485)$ has wisely observed: "Expect students to hold themselves to standards of discipline ... precise thinking [and] rigorous analysis and to question, propose, and challenge ideas, and you will increase the likelihood they will excel."

\section{Notes}

1. For the purposes of this paper, we define a large lecture class as one which is taught in a large lecture hall to more than 100 students.

2. These techniques have been developed by the senior author of this paper. The junior author has served as a teaching assistant in the class and has shared fully in the development of this study.

3. Two or three teaching assistants are used each semester. The rough ratio is one teaching assistant for every 50 students in the course.

4. These results are similar to student evaluations in other large lecture sections of American government taught with similar techniques. Results for all classes taught using these techniques are available upon request from the senior author.

5. In the spring semester of 1996 we assigned seven papers rather than the normal six papers. This was done simply on an experimental basis.

6. For example, in the field of judicial politics, Katsh (1997) has edited an excellent set of readings on major legal controversies.

7. With a class of 150 students, three teaching assistants were used. This created a much more complicated debate/paper structure, but it was used successfully.

\section{References}

Cronin, Thomas. 1991. "On Celebrating College Teaching." PS: Political Science and Politics 24(3): 482-91.

DiClerico, Robert E., and Allan S. Hammock. 1995. Points of View: Readings in American
Government and Politics. 6th ed. New York: McGraw-Hill.

Janda, Kenneth, Jeffrey M. Berry, and Jerry Goldman. 1997. The Challenge of Democracy: Government in America. 5th ed. Boston: Houghton Mifflin.

Katsch, M. Ethan. 1997. Taking Sides: Clashing Views on Controversial Legal Issues. 7th ed. Guilford, CT: Dushkin Publishing.

Levine, Herbert M. 1995. Point-Counterpoint: Readings in American Government. 5th ed. New York: St. Martin's Press.

McKenna, George, and Stanley Feingold. 1995. Taking Sides: Clashing Views on Controversial Political Issues. 9th ed. Guilford, CT: Dushkin Publishing.

Miroff, Bruce, Raymond Seidelman, and Todd Swanstrom. 1997. Debating Democracy: A Reader in American Politics. Boston: Houghton Mifflin.

\section{About the Authors \\ Thomas R. Hensley \\ is professor of polit- ical science at Kent State University. His primary research interests are in the field of judicial poli- tics, and his most recent book is The Changing Supreme Court: Constitutional Rights and Liberties (West/Wadsworth, 1997), coauthored with Chris Smith and Joyce Baugh. He has been recipient of numerous teaching awards, including being named 1991 Ohio Professor of the Year by CASE, the Council for the Support and Advancement of Higher Educa- tion.}

\section{Maureen Rand}

Oakley is a Ph.D. student at Kent

State University.

Her areas of research include reproductive policy, state policy diffusion, and gender politics. She has recently presented a paper at the 1997 annual meeting of the APSA entitled

"Explaining State Fetal Protection Statutes." She is currently coauthoring a book chapter on the impact of gender and occupational segregation on political attitudes for a forthcoming edition of Women in Politics: Outsiders or Insiders?, edited by Lois Duke Whitaker (3rd ed., Prentice Hall, 1998). 